\title{
Diagnostic challenge: bilateral infected lumbar facet cysts - a rare cause of acute lumbar spinal stenosis and back pain
}

\author{
Brett A Freedman, Tuan L Bui, S Timothy Yoon
}

\begin{abstract}
Symptomatic synovial lumbar facet cysts are a relatively rare cause of radiculopathy and spinal stenosis. This case and brief review of the literature, details a patient who presented with acutely symptomatic bilateral spontaneously infected synovial facet (L4/5) cysts. This report highlights diagnostic clues for identifying infection of a facet cyst.
\end{abstract}

\section{Introduction}

Lumbar facet cysts are a less common but well documented cause of compressive radiculopathy and lumbar spinal stenosis, with approximately 500 total cases reported in the literature [1-5]. The lumbar facet is a synovial-lined zygoaphophyseal joint, comprising the articulation between the inferior and superior articulating processes of the spinal vertebrae. The facet joint, like synovial lined joints of the appendicular skeleton, are prone to cyst formation as a manifestation of osteoarthritis. To date, infection of a lumbar facet cyst has not been reported in the literature. This case illustrates the clinical findings and outcomes associated with bilateral infected lumbar facet cysts.

\section{Case Report \\ History}

Our patient is a 63 year old overweight gentleman who presented to the emergency room with a three day history of progressive low back pain and pain radiating down the right worse than left leg in an L5 distribution. He also noted an acute onset of drop foot. He rated his pain as 10 out of 10 . He reported that he has had a history of intermittent back pain, but no prior leg symptoms. He has diabetes, which was marginally controlled (HgbA1C was 7.4), coronary artery disease and one week prior to presentation he completed an 8 week course of radiation therapy for prostate cancer.

\footnotetext{
* Correspondence: styoon@emory.edu

Department of Orthopaedic Surgery, Emory University School of Medicine, Emory Spine Center, Altanta, GA 30329, USA
}

\section{Physical Examination}

On examination, he was in significant pain. He had bilateral lower extremity weakness. His motor strength testing revealed 4/5 left and right iliopsoas and 4+/5 left and right quadriceps, hamstrings and gastrocnemius muscles, all of which appeared to be pain induced reductions of strength. Additionally, he had 3/5 left and right tibialis anterior (TA) and extensor hallucis longus (EHL) function. His peroneals were also weak (4-/5). He had normal sensation to light touch and pin prick. His deep tendon reflexes were $2+$ bilaterally. He had a normal upper extremity neurological and digital rectal exam.

\section{Imaging and Labs}

Plain radiographs and a CT scan demonstrated severe arthrosis at the L4/5 facet joints. (Figure 1) MRI revealed what appeared to be large degenerative bilateral L4/5 facet cysts with extensions into the interspinous and epidural space, causing severe compression of the thecal sac. (Figure 1 and 2) There was paravertebral muscle heterogenous hyperintensity on fat-suppressed T2 images. He was afebrile and had normal white cell count and blood sugars. Due to the unusual acuity of symptom presentation, potential for immune compromise given his medical co-morbidities and subtle MRI findings suggestive of local inflammatory response in the paravertebral muscles, an ESR and CRP were obtained. They were both markedly elevated. (ESR 103 $\mathrm{mm} / \mathrm{hr}$; CRP $33.2 \mathrm{mg} / \mathrm{dL}$ ) His admission and subsequent laboratory results are located in Table 1. 


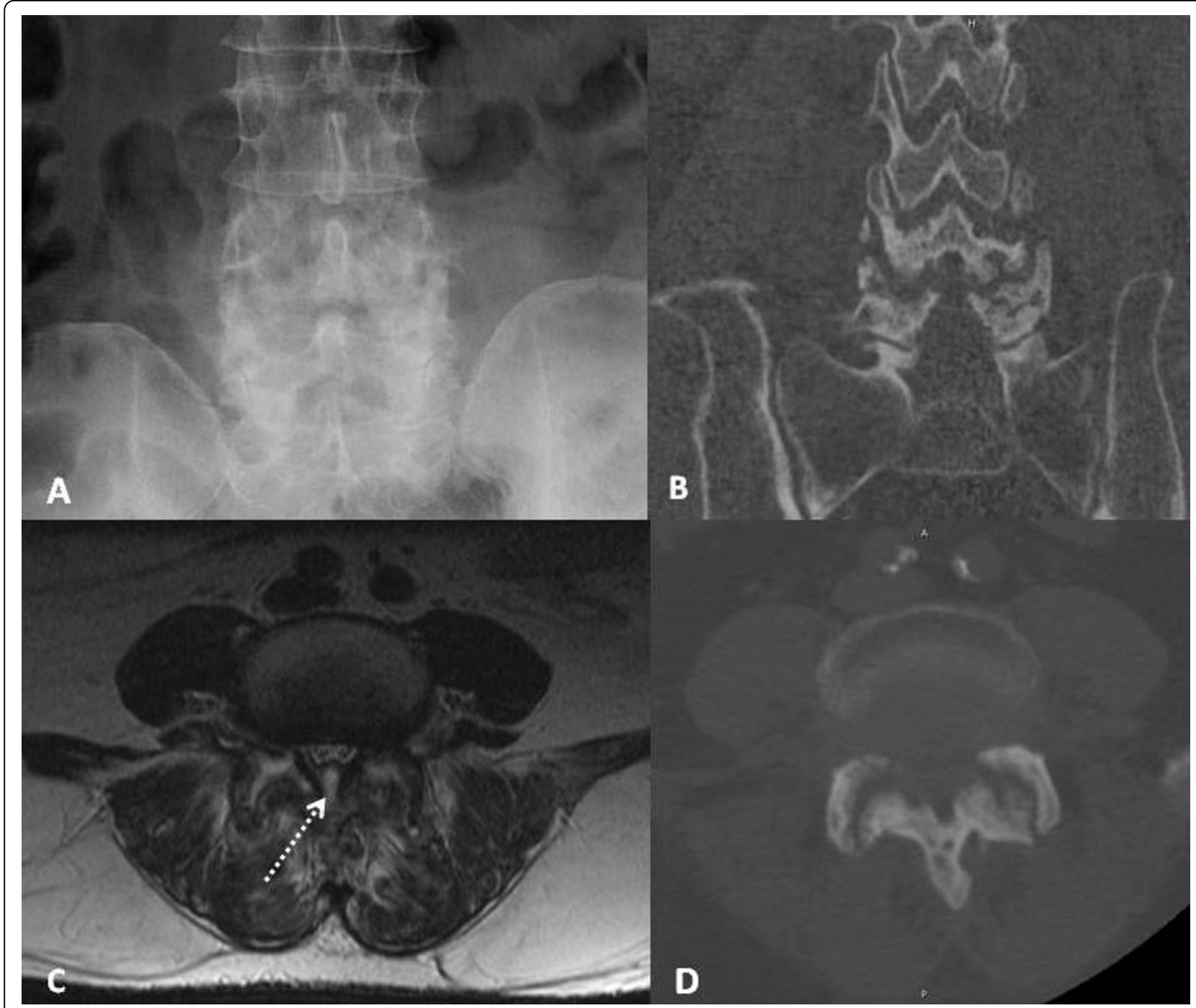

Figure 1 Advanced degenerative changes of the L4/5 facets are seen on these AP radiograph and CT scan images. (1A, B and D) Note the subchondral sclerosis and cystic changes. The axial T2 MRI image shows a focal fluid-like collection in bilateral L4/5 facet joints with contiguous extension into the midline dorsal epidural space (dotted line) (1C). Additionally, there is heterogeneous increased signal in the paravertebral muscles. There is no evidence of spondylodiscitis or paravertebral muscle abcess.

\section{Operation and Pathological Findings}

The clinical exam, imaging studies and laboratory findings all suggested this patient's symptoms were due to a L4/5 degenerative facet cyst causing symptomatic lumbar stenosis; however the markedly elevated CRP and ESR and inflammatory signal on MRI was worrisome for an infectious etiology. He was admitted to the hospital and taken to the OR the following day for a decompression and possible fusion of L4/5. Intraoperatively, exposing the $\mathrm{L} 4 / 5$ facets revealed voluminous cysts that expressed frank pus upon incision. As a result, we decided to stage this patient's surgeries. At the first stage we performed subtotal L4 and L5 laminectomies, near-total facet capsulectomy, partial facetectomy and thorough lavage to widely eradicate the infected structures. The infection appeared to be completely contained within the facet cysts. Tissue samples were sent for culture and pathology, which grew out MethicillinResistant Staphylococcus Aureus (MRSA). Pathology showed chronic and acute inflammatory changes without evidence of neoplasm. Infectious disease was consulted and he was started on intravenous Vancomycin, which was continued for a total of 6 weeks. Two days following the initial procedure, he underwent a direct lateral interbody fusion (X-LIF, NuVasive, Inc, San Diego, CA) with BMP-2 (InFuse, Medtronic, Inc, Minneapolis, $\mathrm{MN}$ ) and posterior pedicle screw instrumentation. 


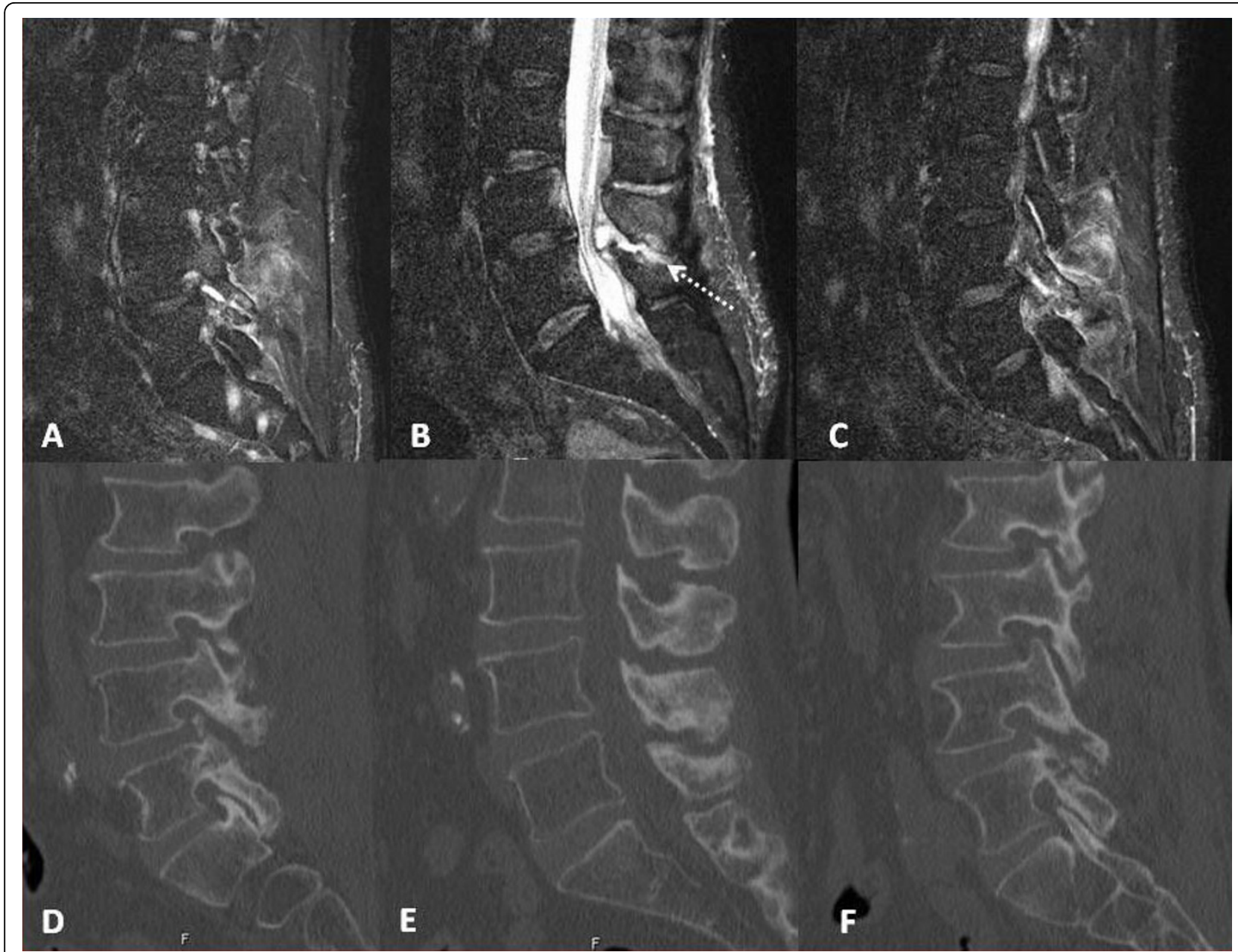

Figure 2 Right to left sagittal T2 MRI images with their associated CT sagittal reconstructions beneath, show the fluid-like (isodense and isointense to CSF) signal in the right greater than left facet joints, as well as diffusely increased signal in the adjacent paravertebral muscles. (2A and C) The midline sagittal MRI image shows the compressive epidural portion of the cyst, with a stalk that trails into the interspinous space (dotted line), where it communicates with the facet cysts. (2B) The CT images show non-specific chronic destructive changes to the $L 4 / 5$ facet, typical of uncomplicated lumbar facet cysts. (2D, E and F)

\section{Postoperative Course}

After his decompression surgery, the patient did well, with cessation of radicular symptoms, and was discharged on the $4^{\text {th }}$ postoperative day following the subsequent X-LIF. Upon discharge from the hospital, his pain level improved to $5 / 10$, with pain solely in his back. His motor strength normalized in all groups except for EHL, TA and P, which only improved to 4/5. However, this was sufficient to eliminate his drop foot gait. At his 2 week clinic appointment, he was afebrile and his wound was healing without complication.

Unfortunately, our patient was a visitor to this country who permanently resided in the Virgin Islands. He had been here for his cancer treatments, but upon resolution of his back and leg symptoms, he returned to his home. He was scheduled to return to our clinic 2 weeks, 6 weeks, and 3 and 6 months postoperatively, but only came for a 2 and 8 week visit. At his 8 week visit, he had completed his IV antibiotic therapy two weeks prior and denied any pain. He rated pain in his legs and back as $0 / 10$. He still had some slight L5 weakness $(4+/ 5$ EHL, TA) on examination; however, this did not affect his gait. His laboratory values had normalized. (Table 1) Due to his living situation, follow-up at 3 and 6 months was obtained telephonically and demonstrated no evidence of recurrent leg symptoms or infection.

\section{Discussion}

The clinical presentation, management and outcomes of aseptic lumbar facet cysts have been reported [1-6]. In 2004, Epstein performed a comprehensive review of the 15 published case series, which provides defining characteristics of this pathology [2]. Facet cysts are detected in $0.6-10 \%$ of MRI scans of the lumbar spine [1-7]. 
Table 1 Pertinent lab values

\begin{tabular}{lllll}
\hline & $\begin{array}{l}\text { Emergency } \\
\text { Department }\end{array}$ & POD\#1 & $\begin{array}{l}\text { At } \\
\text { Discharge }\end{array}$ & $\begin{array}{l}\mathbf{8} \text { week } \\
\text { follow-up }\end{array}$ \\
\hline WBC $(/ \mathrm{mcL})$ & 9,800 & 7,700 & 7,200 & 7,600 \\
\hline $\mathrm{CRP}(\mathrm{mg} / \mathrm{dL})$ & 33.2 & 19.6 & 16.5 & $\begin{array}{l}.27(0.033 \\
\text { at } 3 \mathrm{mo})\end{array}$ \\
\hline
\end{tabular}

$\operatorname{HgA1C}(\%) \quad 7.4$

POD\#1 = postoperative day one, $\mathrm{WBC}=$ white blood count (normal value $<11,100 / \mathrm{mcL}$ ), CRP = C-reactive Protein (normal value $<0.8 \mathrm{mg} / \mathrm{dL}$ ), $\mathrm{HgA} 1 \mathrm{C}$ (Hemoglobin A1C, therapeutic goal $<6 \%$ ).

The L4/5 level is most commonly affected and cysts most commonly occur in patients 60-65 years of age $[1-3,5,8]$. L5 radiculopathy is the most common primary complaint, although $95-100 \%$ of patients will have low back pain, as well $[1,2,9]$.

Facet sagittal orientation ( $>45$ degrees) and facet arthrosis are present in over $77 \%$ of patients with symptomatic lumbar facet cysts [9-11]. As in the appendicular skeleton, the primary response of synovial joints to arthritis, is the over-production of synovial fluid, which in turn raises the intra-capsular pressure. In some patients, weak or thin areas in the facet capsule give way, the result is a focal mushroom-like swelling $[1,12]$. With time cystic fluid dehydrates, and the cyst itself undergoes myxoid degeneration. Classic cystic appearance on MRI (isodense and isointense with CSF) occurs in as few as $57 \%$ of facet cysts [9]. These space occupying lesions can compress nerve roots, causing radiculopathy (57-75\%) or neurogenic claudication (25\%) $[2,9,13]$.

Although cases of successful nonoperative treatment have been reported with steroid injections or imageguided aspiration, for the most part, symptomatic synovial cysts require excision $[1,2,9,14]$. While agreement exists for surgical intervention of symptomatic facet cysts, the extent of surgery needed is debatable. Surgeons tend to favor either decompression alone or decompression and fusion, with decompression alone being the more commonly reported approach $[1,5]$. Concurrent spondylolisthesis, especially in the presence of significant low back pain, is the most common reason for adding an arthrodesis $[1,3,5,12]$. The lack of prospective cohort studies require surgeons to base their treatment plan on hypothesis and interpretation of case series which report good-excellent results (in $>75 \%$ of cases) for both approaches $[1,5,12]$. Those who advocate arthrodesis tend to point to two primary issues. First, the cyst is only an effect, the true cause is the underlying facet arthrosis and possibly instability [3,12]. Simply excising the cyst will not treat the cause. Conversely, the rate of recurrence following laminectomy alone appears to be quite low, averaging < $3 \%$ across published series $[1,13]$. Second, patients with lumbar facet cysts overwhelmingly have abnormal motion segments and low back pain $[2,3,9,12]$. Excision and decompression alone does not address these concomitant pathologies and may worsen segmental instability $[3,9]$. However, the rate of re-operation for symptomatic instability appears to be low as well ( $2 \%$ in Lyons et al. series of 194 patients) [5].

Our patient had chronic low back pain, sagittally oriented facets ( $>45$ degrees) with extensive cystic and sclerotic changes. We performed significant facetectomies and near-total capsulectomy to widely debride the infection; thus we elected to fuse his spine. His recent XRT exposure and his underlying marginally controlled diabetes made him vulnerable to infectionClass B host [15]. Hypertrophic synovium in facet cysts, devoid of a basement membrane, allowed MRSA to localize and develop into a closed space infection. This sequence of hematogenous seeding and subsequent infection is common to other synovial joints [16]. This case clearly demonstrates that this can occur in lumbar facet joints, as well. Further, debridement of the infected tissue, prolonged culture-specific antibiotic and stabilization through instrumented spinal fusion can successfully eradicate this rare form of infection and result in an excellent clinical outcome (= complete symptom resolution, no recurrence) $[1,12]$.

This case report highlights diagnostic clues that suggest infection of an underlying facet cyst. The key findings appear to be rapid progression of symptoms, associated elevation in CRP and ESR and paravertebral muscles edema. Symptomatic neurological compression in uncomplicated facet cysts develops over time as degeneration progresses. Only $7 \%$ of cases present within 7 days of symptom onset, perhaps dues to intracystic hemorrhage $[1,9,17]$. In patients presenting with acutely progressive lumbar stenotic or radiculopathic symptoms which are attributed to lumbar facet cysts, the possibility of infection of the cysts should be considered and evaluated.

\section{Consent}

Written informed consent to publish could not be obtained despite reasonable attempts. The patient cannot be identified from the case report and there is no reason to believe that they would object to its publication.

\section{Acknowledgements}

We would like to acknowledge Bettie Cheek, RN for her assistance with this project.

No funding was received in support of this project.

Authors' contributions

All authors contributed in writing this case report, and have all read and approved the final manuscript. 


\section{Competing interests}

The authors declare that they have no competing interests.

Received: 18 July 2009 Accepted: 5 March 2010

Published: 5 March 2010

\section{References}

1. Boviatsis EJ, Staurinou LC, Kouyialis AT, Gavra MM, Stavrinou PC, Themistokleous M, Selviaridis P, Sakas DE: Spinal synovial cysts: pathogenesis, diagnosis and surgical treatment in a series of seven cases and literature review. Eur Spine J 2008, 17(6):831-7.

2. Epstein NE: Lumbar Synovial Cysts. A Review of Diagnosis, Surgical Management and Outcome Assessment. J Spinal Disord Tech 2004, 17:321-325.

3. Epstein NE: Lumbar laminectomy for the resection of synovial cysts and coexisting lumbar spinal stenosis or degenerative spondylolisthesis: an outcome study. Spine 2004, 29(9):1049-55.

4. Eyster EF, Scott WR: Lumbar synovial cysts: report of eleven cases. Neurosurgery 1989, 24:112-115.

5. Lyons MK, Atkinson JL, Wharen RE, Deen HG, Zimmerman RS, Lemens SM: Surgical evaluation and management of lumbar synovial cysts: the Mayo Clinic experience. J Neurosurg 2000, 93(suppl 1):53-57.

6. Banning CS, Thorell WE, Leibrock LG: Patient outcome after resection of lumbarjuxtafacet cysts. Spine 2001, 26:969-972.

7. Doyle AJ, Merrilees M: Synovial cysts of the lumbar facet joints in a symptomatic population: prevalence on magnetic resonance imaging. Spine 2004, 29:874-878.

8. Deinsberger $R$, Kinn $E$, Ungersböck K: Microsurgical treatment of juxta facet cysts of the lumbar spine. J Spinal Disord Tech 2006, 19(3):155-60.

9. Metellus P, Fuentes S, Adetchessi T, Levrier O, Flores-Parra I, Talianu D, Dufour H, Bouvier C, Manera L, Grisoli F: Retrospective study of 77 patients harbouring lumbar synovial cysts: functional and neurological outcome. Acta Neurochir (Wien) 2006, 148:47-54.

10. Fujiwara A, Tamai K, An HS, Lim TH, Yoshida H, Kurihashi A, Saotome K: Orientation and osteoarthritis of the lumbar facet joint. Clin Orthop Relat Res 2001, , 385: 88-94.

11. Fujiwara A, Tamai K, An HS, Kurihashi T, Lim TH, Yoshida H, Saotome K: The relationship between disc degeneration, facet joint osteoarthritis, and stability of the degenerative lumbar spine. J Spinal Disord 2000, 13(5):444-50.

12. Khan AM, Synnot K, Cammisa FP, Girardi FP: Lumbar synovial cysts of the spine: an evaluation of surgical outcome. J Spinal Disord Tech 2005, 18(2):127-31.

13. Howington JU, Connolly ES, Voorhies RM: Intraspinal synovial cysts: 10year experience at the Ochsner Clinic. J Neurosurg 1999, 91(2 Suppl):193-9.

14. Parlier-Cuau C, Wybier M, Nizard R, Champsaur P, Le Hir P, Laredo JD: Symptomatic lumbar facet joint synovial cysts: clinical assessment of facet joint steroid injection after 1 and 6 months and long term followup in 30 patients. Radiology 1999, 210:509-513.

15. Cierny G, Mader JT: Approach to adult osteomyelitis. Orthop Rev 1987, 16(4):259-70.

16. Zink BJ, Weber JE: Chapter 130 - Bone and Joint Infections. Rosen's Emergency Medicine: Concepts and Clinical Practice St Louis, MO: Mosby, IncMarx JA , 5 2002, 1925-43.

17. Ramieri A, Domenicucci M, Seferi A, Paolini S, Petrozza V, Delfini R: Lumbar hemorrhagic synovial cysts: diagnosis, pathogenesis, and treatment. Report of 3 cases. Surg Neurol 2006, 65:385-390.

doi:10.1186/1749-799X-5-14

Cite this article as: Freedman et al:: Diagnostic challenge: bilateral infected lumbar facet cysts - a rare cause of acute lumbar spinal stenosis and back pain. Journal of Orthopaedic Surgery and Research 2010 5:14.

\section{Submit your next manuscript to BioMed Central and take full advantage of:}

- Convenient online submission

- Thorough peer review

- No space constraints or color figure charges

- Immediate publication on acceptance

- Inclusion in PubMed, CAS, Scopus and Google Scholar

- Research which is freely available for redistribution 